\title{
Use of geochemical fingerprints to trace sediment sources in an agriculture catchment of Argentina
}

\author{
Romina Torres Astorga ${ }^{1}$, Yanina Garcias $^{1}$, Gisela Borgatello ${ }^{1}$, Hugo Velasco $^{1(*)}$, Román Padilla $^{2}$, Gerd \\ Dercon $^{3}$, Lionel Mabit ${ }^{3}$ \\ ${ }^{1}$ IMASL, UNSL, CONICET. Ej. de los Andes 950, San Luis, Argentina. \\ ${ }^{2}$ Nuclear Science and Instrumentation Laboratory, Division of Physical and Chemical Sciences, IAEA, Seibersdorf, \\ Austria \\ ${ }^{3}$ Soil and Water Management \& Crop Nutrition Laboratory, Joint FAO/IAEA Division of Nuclear Techniques in \\ Food and Agriculture, Seibersdorf, Austria \\ ${ }^{(*)}$ rh.velasco@gmail.com
}

\begin{abstract}
Soil erosion and associated sediment redistribution are key environmental problems in Central Argentina. Specific land uses and management practices, such as intensive grazing and crop cultivation, are considered significantly driving and accelerating these processes.

This research focuses on the identification of suitable soil tracers from hot spots of land degradation and sediment fate in an agricultural catchment of central Argentina with erodible loess soils. Using Energy Dispersive X-Ray Fluorescence (EDXRF), elemental concentrations were determined and further used as soil tracers for geochemical characterization.

The best set of tracers were identified using two artificial mixtures composed of known proportions of soil sources collected in different sites having distinctive soil uses. Phosphorus, iron, calcium, barium, and titanium were identified for obtaining the best suitable reconstruction of the source proportions in the artificial mixtures. Then, these elements as well as the total organic carbon were applied for pinpointing critical hot spots of erosion within the studied catchment. Feedlots were identified to be the main source of sediments, river banks and dirt roads together are the second most important source. This investigation provides key information for optimizing soil conservation strategies and selecting land management practices and land uses which do not generate great contribution of sediment, preventing pollution of the waterways of the region.
\end{abstract}

Keywords: fingerprinting; geochemical elements; energy dispersive X-ray fluorescence; soil erosion; mixing models

\section{Introduction}

In the South America Dry Chaco, one of Earth's largest semiarid woodland, the native vegetation is rapidly being converted to pastures and croplands (Baldi \& Jobbágy, 2012; le Polain de Waroux et al., 2016). As consequence of the global increase in food demand and the incorporation of new agricultural technologies, among other factors, during the last 30 years this region has had a depletion rate of the $2.2 \%$, in average, in native woodlands per year (Gasparri \& Grau, 2009; Zak et al., 2004).

Additionally, in the southern limit of this region, in central Argentina, the agricultural frontier continues to expand westward from the humid Pampas toward arid and semi-arid environments is spite of the higher water limitation. In many cases, land practices adopting similar agricultural strategies to those applied in the more humid regions which increase the risk of environmental deterioration (Viglizzo et al., 2011). After decades of these changes in the land use it is necessary to have suitable indicators of the impact of these practices on the soil status and water quality. These indicators should provide reliable information for effective decision making that could lead to a sustainable development, contributing in this way to the reduction of the existing tensions between the productive development and environmental protection. Soil erosion magnitude is one of the most evident indicators of the environment degradation. In this region 
with high vulnerability, erosion can significantly increase by inappropriate land use management which results in reduced cropland productivity and contributes to the pollution of streams, rivers and water reservoirs. In order to implement effective strategies for controlling excessive flow of sediment, it is necessary to determine both the nature and location of the main sources of sediments at the watershed scale and its relationship with the land uses.

Geochemical fingerprinting method has been used widely to determine sediment provenance(Hardy et al., 2010). Elemental concentrations in the areas where the sediments originate from and where they accumulate, allow to identify and to quantify the relative contribution from different sources. These concentrations are mainly conditioned by the type of soils, the geological substratum and the land uses from which they originate (Blake et al., 2012). Applying mixing models (MM) allows to derive the relative contributions of different sources to the sediment mixtures in the fate places.

In this paper, we applied a geochemical fingerprints approach to characterize the temporal sediment apportionment in a small basin located in the Province of San Luis, in Argentina central. In this relatively small mountain catchment, different land uses have been incorporated at the expense of native vegetationsince the 60s, with greater intensity in the last 20 years. Soils are currently being used for agriculture (no tillage crop rotation), livestock, and some fields used to exploit fruit trees. Original vegetation occupies important extensions of the region. To evaluate the impact of different land uses in the sediment contribution, the source samples were collected in the region of Durazno sub-catchment where loessoid material soils are dominant (i.e. Quaternary deposits). Thus, no differences in lithologies were studied.

The two major objectives of the investigation were: (a) to identify the most efficient set of fingerprint elements using artificial soil mixtures (Torres Astorga et al., 2018) and (b) to use these suitable soil tracers to describe the temporal sediment apportionment in different locations in the hydrographic network that includes streams of stationary character, rivers with very variable flows and artificial bodies of water that serve for their regulation.

\section{Study Area}

The selected study site is Durazno Sub-catchment (previously called Estancia Grande Sub-catchment), covering 1235 hectares, which is located in the centre of Argentina $23 \mathrm{~km}$ north east of San Luis city (S $33^{\circ} 10^{\prime}$; W $66^{\circ} 08^{\prime}$ ) at 1100 m.a.s.l.. The studied sub-catchment is part of the Rio Volcán Sub-catchment (Fig. 1). Rio Volcán Sub-catchment present 5 different lithological units: granites, gneisses, micaschists, mafic and ultramafic rocks, and quaternary deposits (Morosini et al., 2017). The average annual temperature is $17{ }^{\circ} \mathrm{C}$, while in summer (December to March) the mean temperature is $23{ }^{\circ} \mathrm{C}$. Annual rainfall ranges from 600 to $800 \mathrm{~mm}$, with a tendency to increase and a rising frequency of extreme rainfall events during the last decades(de la Casa \& Ovando, 2014; Penalba \& Vargas, 2004).Precipitation regimes vary seasonally, with a dry season from May to October, with almost no precipitation, but some occasional drizzles, and a rainy season from November to April. The studied sub-catchment is characterized by highly erodible Eutric Fluvisol soils. These soils originated from silty sand material and possess a high level of organic matter in their upper $25 \mathrm{~cm}$. The studied catchment belongs to the loess belt of North East Argentina (Teruggi, 1957), and there is no rocky outcrop in the investigated area, being secondary loessoid deposits. Figure 1 displays that Durazno sub-catchment has 2 different lithological units; mainly Quaternary deposits and a small portion with Gneiss. The soil is composed of silt-sandy materials of river rework origin (Torres Astorga et al., 2018).

The region is currently being used mainly for agriculture (crop rotation), livestock (rangelands, pastures and feedlots) are another important land use, also some of the agricultural fields are used for growing nut orchards (walnuts and almonds) (Fig.2). Furthermore, native vegetation is found in between the agriculture lands and in the upper part of the sub-catchment. Regarding cropping and its soil management practices: for more than 10 years direct seeding mulch-based systems have been adopted as the main practice for crop cultivation. This practice has increased crop yield and reduced soil erosion. The chosen 
crops are soybean, maize, and wheat. The herbicides used by most of the farmers are atrazine and glyphosate. Fertilizers are not applied with the same regularity on all the agricultural fields. Farmers mainly use N-P-K-based fertilizers such as urea ammonium nitrate (UAN) 32-0-0, monoammonium phosphate (MAP) 11-52-0, triple superphosphate 0-46-0, and biological growth promoters depending on the type of crop cultivated. Feedlot cattle are fed with maize, oats, sunflower meal, and grazing hay. Mineral supplements of sodium chloride, calcium, phosphorus, and magnesium are also given to the cattle.

\section{Materials and Methods 3.1. Sampling}

The sampling procedure involved removing the leaves and plant material that was found in the place before taking a soil layer of $20 \mathrm{~cm}^{2}$ and $2 \mathrm{~cm}$ thick of exposed soil using a stainless-steel flat spatula. At each sampling location, multiple subsamples from a surface of about 100-200 $\mathrm{m}^{2}$ were collected in a plastic bucket to obtain a composite sample representative of that land use (source samples). Sediment samples (mixture samples in the river courses) were collected at the top $20 \mathrm{~mm}$ of the accumulation zones on little floodplains where deposition processes were observed.

The sediment samples (mixtures) were taken during three different periods: (a) end of rainy season (b) end of dry season, and (c) middle of rainy season. The location of the sediment sampling points is presented in Figure 2. In the first period (a) sediment sample collection in the northern part of the river (Mixtures 4 and 5) was not possible.

Four of the source samples i.e. S1, S2, S3, and S4 were used to create two artificial mixtures (MIX 1 and MIX 2).A total of 71 samples were collected from sources soils and mixture sediments. The number of samples was decided based on the extension of each land use.

\subsection{Analytical methods}

The samples were dried at $50{ }^{\circ} \mathrm{C}$, disaggregated, and then sieved through a 2-mm sieve at the GEAIMASL Laboratory. Two artificial mixed samples (MIX 1 and MIX 2) were then composed using identified source samples following the below proportions:

$$
\mathrm{MIX} 1=10 \% \mathrm{~S} 1+25 \% \mathrm{~S} 2+40 \% \mathrm{~S} 3+25 \% \mathrm{~S} 4
$$

$\mathrm{MIX} 2=3 \% \mathrm{~S} 1+45 \% \mathrm{~S} 2+20 \% \mathrm{~S} 3+32 \% \mathrm{~S} 4$

The soil source S1 originated from a riverbank. The sources S2 and S4 were two soil samples collected from crop rotation commercial farms. During the sampling, one of these sources was under corn and the other one under soybean cultivation, respectively. These cultivations swap between corn and soybean yearly. The source S3 came from a feedlot. The proportions were selected to represent the possible distributions of sediment origin, including the end members of sediment contribution and to ensure as well that the model testing gets results outside the uncertainty margins of the model. The total organic carbon (TOC) was determined at the IAEA Soil and Water Management \& Crop Nutrition Laboratory. For EDXRF spectrometry analysis, the samples were ground into fine powder and pressed pellets of $25 \mathrm{~mm}$ diameter and $2.5 \mathrm{~g}$ weight were produced. These pellets were measured at the IAEA Nuclear Science and Instrumentation Laboratory using a heavy-duty, fully software-controlled EDXRF spectrometer utilizing five secondary targets (SPECTRO X-LAB 2000). The concentration of more than 40 elements for each sample was obtained.

A three steps procedure was applied for fingerprints selection: 1- Kruskal Wallis $\mathrm{H}$ test was performed to dismiss fingerprint properties that were redundant. This procedure is a nonparametric method equivalent to analysis of variance (ANOVA). 2- Discriminant Function Analysis was used to test the power of the parameters that passed the previous test to classify all the source samples into the correct categories.3- $\mathrm{Bi}$ - 
plots examination that consists of a visual analysis of 2-D plots of the elements that were statistically selected. All possible combinations of element pairs as bi-plots were created taking into account that if a mixture lies outside the sources polygon, then one or both of the elements pair should not be used (Torres Astorga et al., 2018).

The resulting elements were validated using the two artificial mixtures in two MMs: CSSIAR v2.00(de los Santos-Villalobos et al., 2017) and IsoSource(Phillips \& Gregg, 2003). After validation, CSSIAR v2.00was then applied for identifying critical hot spots of erosion using the selected geochemical elements and TOC data as fingerprints in the collected mixture samples from the studied sub-catchment.

\section{Results}

After applying the statistical tests and the bi-plot examination, phosphorus (P), iron (Fe), calcium (Ca), barium (Ba), and titanium (Ti) were selected as best fingerprints. The concentrations of these five elements were used in CSSIAR v2.00 to reconstruct the two artificial mixtures into their original soil sources. The Figure3 presents the calculated proportions. Both MMs derived an accurate and realistic solution when using that set of fingerprints, with a mean absolute error(MAE) of 5.1\% for each of the two artificial mixtures using the CSSIAR software and MAE of 7.5 and $4.5 \%$ for each respective mixture (MIX 1 and MIX 2) using IsoSource.

For the calculated soil proportions, we used the standard deviation output provided by the tested mixing model. It can be noticed that for the artificial mixture MIX 1, the calculated decomposition is accurate as it identifies the main contributor and the source with less proportion in the mixture. For MIX 2, we obtained the same MAE (5,1\%), although this solution is not pointing the main source in the mixture, i.e., corn soil, proposing as the greatest contributor the soybean soil. This swap in these two cropping soils is mainly due to the fact that these soil sources have the same land use with different crops at the moment of sampling (in previous years the crops were switched).The riverbank's contribution to the mixture is in accordance with the actual proportions in both mixtures; in MIX 1, the difference between the calculated and the actual value is only $4 \%$, while in MIX 2 this difference is $1.7 \%$. Furthermore, for feedlot source apportion, the result is close to the actual value; in MIX 1, the absolute difference between the calculated and the actual proportion is $6 \%$, and in MIX 2 only $2 \%$.

Then, the selected elements ( $\mathrm{P}, \mathrm{Ca}, \mathrm{Fe}, \mathrm{Ti}$ and $\mathrm{Ba}$ ) were used as tracers in the catchment to identify the main sediment sources. TOC was used as the sixth fingerprint to improve the accuracy of the results without changing the resulting proportions.

Results on sediment apportionment in channel mixtures are reported in Figure 4.

\section{Discussion}

The selected elemental tracers can be used as suitable fingerprints due to the particular features of the land uses in the study area. Calcium content is lower in the topsoil of the agricultural fields as compared to the soil from the stream banks and native vegetation soils without human intervention. Its content is also high in feedlot soil. Iron shows different concentrations as well. The lower content of Fe may be related to the constant application of fresh manure in the feedlot soils. It is expected a lower Fe content in the trees topsoil (walnuts) than in the native vegetation and grassland top soils. Phosphorus is expected to have highest content in the feedlot due to the cattle manure. An increased $\mathrm{P}$ content in the agricultural fields might be due to the use of fertilizers. Titanium content could be inherited from the parent material and its variability may show differences because of the origin of the loess materials. This would explain the variability in Ti comparing cultivated and uncultivated areas such as riverbanks, dirt roads and native vegetation lands.

From the analysis, feedlots were identified to be one of the main sources of the sediments that reached the water courses. River banks and dirt roads together are the second most important source of sediments, 
particularly at the end of the dry season (period 2) when the vegetation coverage is limited. Both sources jointly, which consist of subsoil material, are the main source of sediments in all three downstream mixtures at the end of dry season. In some cases, rangelands and pasturelands (treated as grazing) are considered as main source in two channel sediment mixtures. Moreover, where grazing is the major contributor the proportions are high (76\% and 60\%). This might be explained by a larger number of animals living in that area and their proximity to the water channel. Other important outcome is the low contribution of the native vegetation and nut orchards sources. This is not surprising as it is not expected to be any soil removal in these zones.

Analysing the temporal changes in the proportions, we can only observe a clear relationship in most of the channel mixtures between the contributions of sediments from subsoils with the dry period of the year. For the rest of the sources, there is no relationship between the land uses and the different periods of the year.

\section{Conclusions}

In this study, geochemical fingerprints approach has been used to explore sediment sources in a small mountain catchment in a semiarid region. Element signatures allow discriminating sources base on different land uses in the same lithology (quaternary deposits). The most relevant results obtained are:

a. The same set of geochemical elements ( $\mathrm{P}, \mathrm{Ca}, \mathrm{Fe}, \mathrm{Ti}$ and $\mathrm{Ba}$ ) allowed approaching the source proportions in artificial mixtures;

b. These tracers, used as sources signatures in the whole catchment, made it possible to identify the feedlots as the main source of sediments in most of the channel sediment mixtures analysed;

c. Together river banks and dirt roads are the second most important source of sediments. Indeed, the limited vegetation cover during every dry season favours sediment movement;

d. Rangelands and pasturelands can be a relevant source of sediments;

e. The area of native vegetation presents one of the lowest contributions to soil erosion.

The identification of the main sources of sediments using the geochemical signature allows the monitoring of the watershed giving relevant information in a relatively quickly and cost-effective way. Nevertheless, given the complexity of the problem and the limitation of the technique, the method should be applied as a complement to other more conventional approaches.

\section{Acknowledgements}

The authors would like to thank the community of farmers that allowed us to collect the samples. The collaboration of Estancia Grande's mayor was important and much appreciated. The authors thank the IAEA Nuclear Science and Instrumentation Laboratory Team (Seibersdorf, Austria) for providing insight and expertise in the EDXRF sample preparation and measurements. The first author would like to acknowledge the STEP (Sandwich Training Educational Programme) fellowship financed by IAEA/ICTP, which allowed the training, measurement and discussion of results at IAEA Seibersdorf Laboratories, Austria.

This investigation has been performed in the framework of the IAEA funded regional Latin American Technical Cooperation Projects [ARCAL RLA 5064 and ARCAL RLA 5076]. This research was supported by CONICET, Argentina [PIP 112201501 00334] and Universidad Nacional de San Luis, Argentina [PROICO 22/F41]. 
1

2

3

4

5

6

\section{References}

Baldi, G., \& Jobbágy, E. G. (2012). Land use in the dry subtropics: Vegetation composition and production across contrasting human contexts. Journal of Arid Environments, 76, 115-127. https://doi.org/10.1016/j.jaridenv.2011.08.016

Blake, W. H., Ficken, K. J., Taylor, P., Russell, M. A., \& Walling, D. E. (2012). Tracing crop-specific sediment sources in agricultural catchments. Geomorphology, 139-140, 322-329. https://doi.org/10.1016/j.geomorph.2011.10.036

de la Casa, A. C., \& Ovando, G. G. (2014). Climate change and its impact on agricultural potential in the central region of Argentina between 1941 and 2010. Agricultural and Forest Meteorology, 195196, 1-11. https://doi.org/10.1016/j.agrformet.2014.04.005

de los Santos-Villalobos, S., Bravo-Linares, C., Meigikos, dos A. R., Cardoso, R., Gibbs, M., Swales, A., Mabit, L., \& Dercon, G. (2017). The CSSIAR v.1.00 Software: A new tool based on SIAR to assess soil redistribution using Compound Specific Stable Isotopes. SoftwareX, 6, 13-18. https://doi.org/10.1016/j.softx.2016.12.005

Gasparri, N. I., \& Grau, H. R. (2009). Deforestation and fragmentation of Chaco dry forest in NW Argentina (1972-2007). Forest Ecology and Management, 258(6), 913-921. https://doi.org/10.1016/j.foreco.2009.02.024

Hardy, F., Bariteau, L., Lorrain, S., Thériault, I., Gagnon, G., Messier, D., \& Rougerie, J.-F. (2010). Geochemical tracing and spatial evolution of the sediment bed load of the Romaine River, Québec, Canada. CATENA, 81(1), 66-76. https://doi.org/10.1016/j.catena.2010.01.005

le Polain de Waroux, Y., Garrett, R. D., Heilmayr, R., \& Lambin, E. F. (2016). Land-use policies and corporate investments in agriculture in the Gran Chaco and Chiquitano. Proceedings of the National Academy of Sciences of the United States of America, 113(15), 4021-4026. https://doi.org/10.1073/pnas.1602646113 
Morosini, A. F., Suárez, A. E. O., Otamendi, J. E., Pagano, D. S., \& Ramos, G. A. (2017). La Escalerilla pluton, San Luis Argentina: The orogenic and post-orogenic magmatic evolution of the famatinian cycle at Sierras de San Luis. Journal of South American Earth Sciences, 73, 100-118.

Penalba, O. C., \& Vargas, W. M. (2004). Interdecadal and interannual variations of annual and extreme precipitation over central-northeastern Argentina. International Journal of Climatology, 24(12), 1565-1580.

Phillips, D. L., \& Gregg, J. W. (2003). Source partitioning using stable isotopes: coping with too many sources. Oecologia, 136(2), 261-269. https://doi.org/10.1007/s00442-003-1218-3

Teruggi, M. E. (1957). The Nature and Origin of Argentine Loess. Journal of Sedimentary Research, 27(3). http://archives.datapages.com/data/sepm/journals/v01-32/data/027/027003/0322.htm

Torres Astorga, R., de los Santos-Villalobos, S., Velasco, H., Domínguez-Quinteros, O., Pereira Cardoso, R., Meigikos dos Anjos, R., Diawara, Y., Dercon, G., \& Mabit, L. (2018). Exploring innovative techniques for identifying geochemical elements as fingerprints of sediment sources in an agricultural catchment of Argentina affected by soil erosion. Environmental Science and Pollution Research, 25(21), pp 20868-20879. https://doi.org/10.1007/s11356-018-2154-4

Viglizzo, E. F., Frank, F. C., Carreño, L. V., Jobbágy, E. G., Pereyra, H., Clatt, J., Pincén, D., \& Ricard, M. F. (2011). Ecological and environmental footprint of 50 years of agricultural expansion in Argentina. Global Change Biology, 17(2), 959-973. https://doi.org/10.1111/j.13652486.2010.02293.x

Zak, M. R., Cabido, M., \& Hodgson, J. G. (2004). Do subtropical seasonal forests in the Gran Chaco, Argentina, have a future? Biological Conservation, 120(4), 589-598. https://doi.org/10.1016/j.biocon.2004.03.034 


\section{$1 \quad$ Figures}

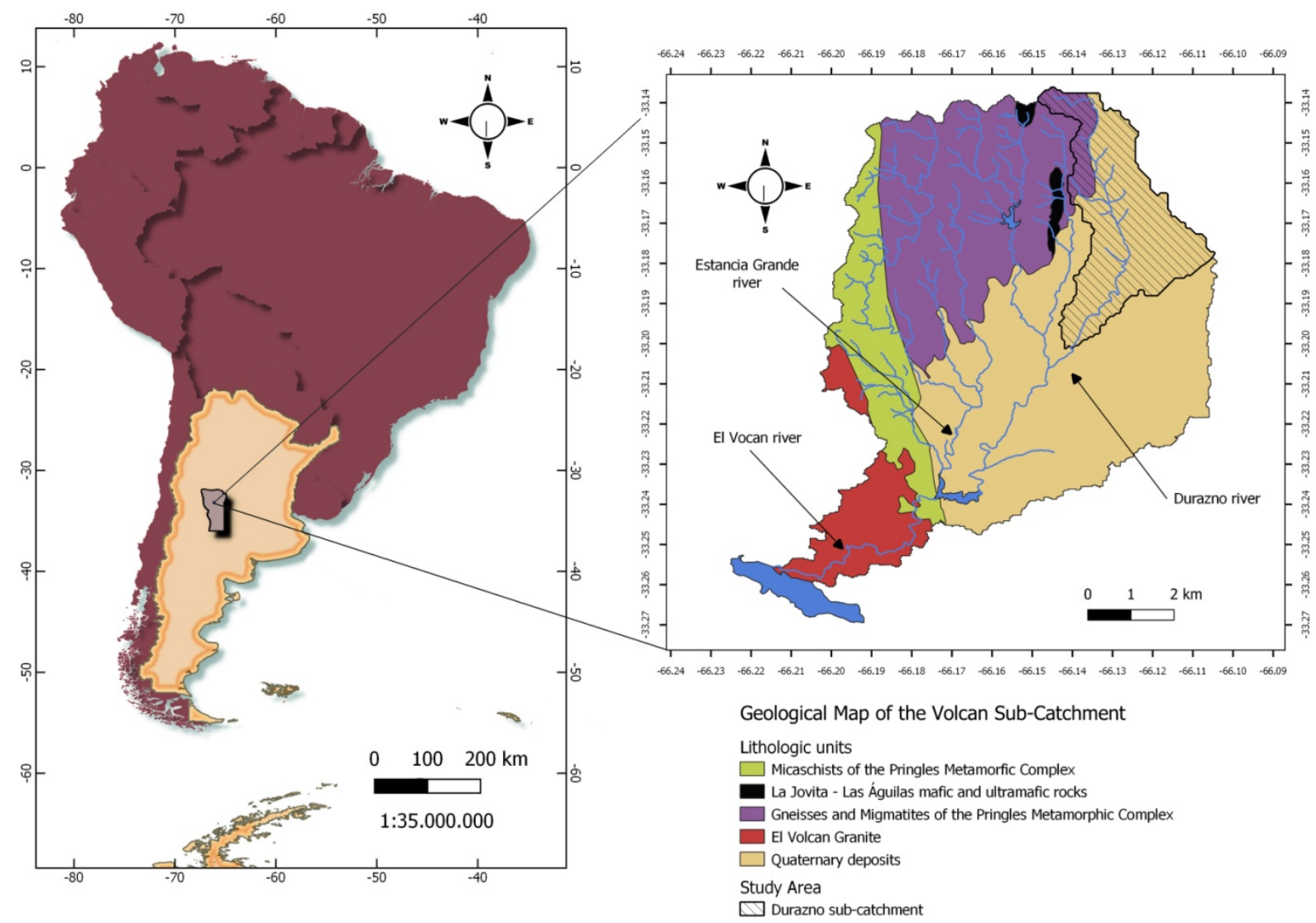

3 Figure 1.Location of the Volcán sub-catchment in San Luis, Argentina and geological map of this subcatchment presenting 5 lithological units. Study area is highlighted with slanted black lines. 


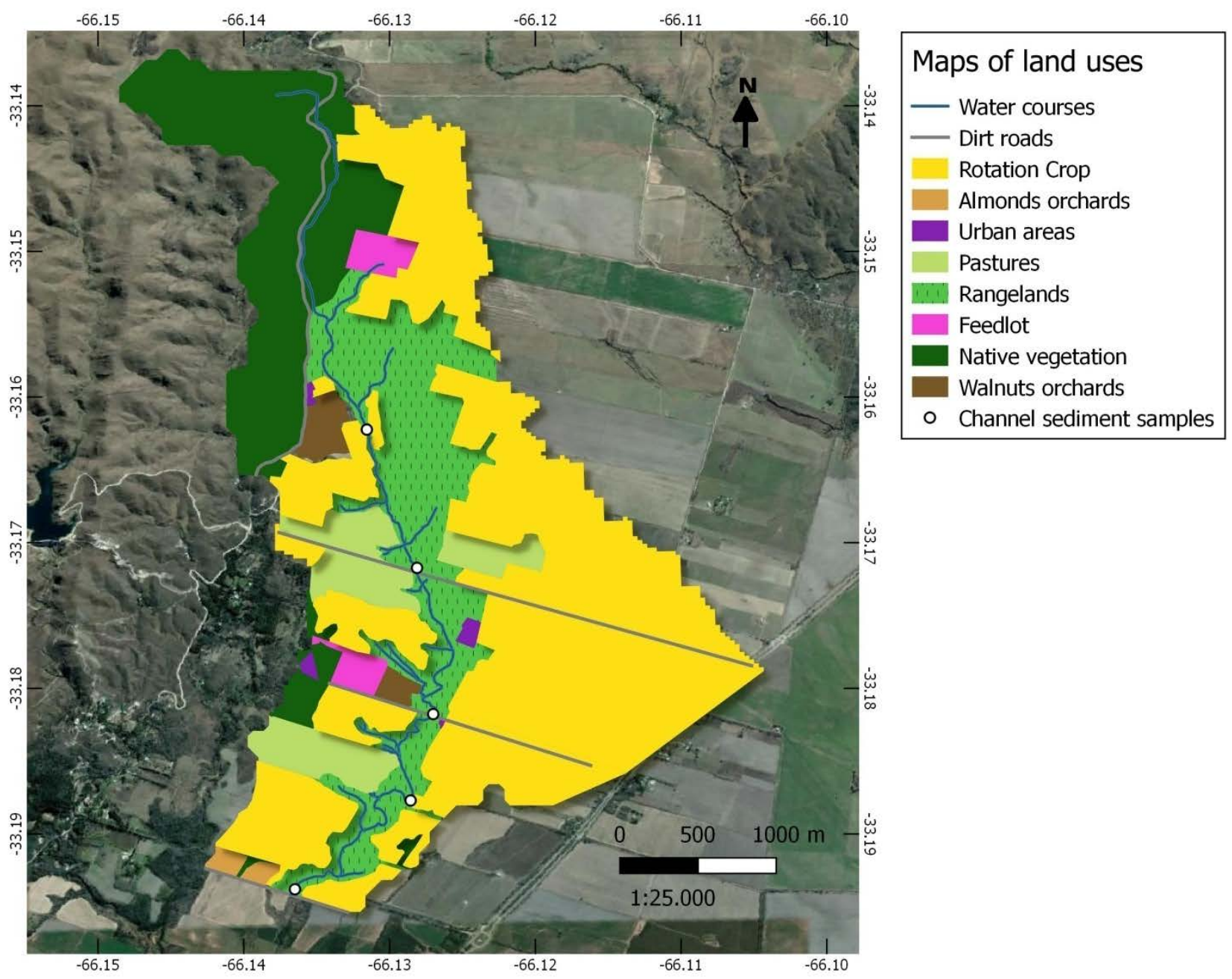

2 Figure 2. Land uses map of Durazno sub-catchment. 

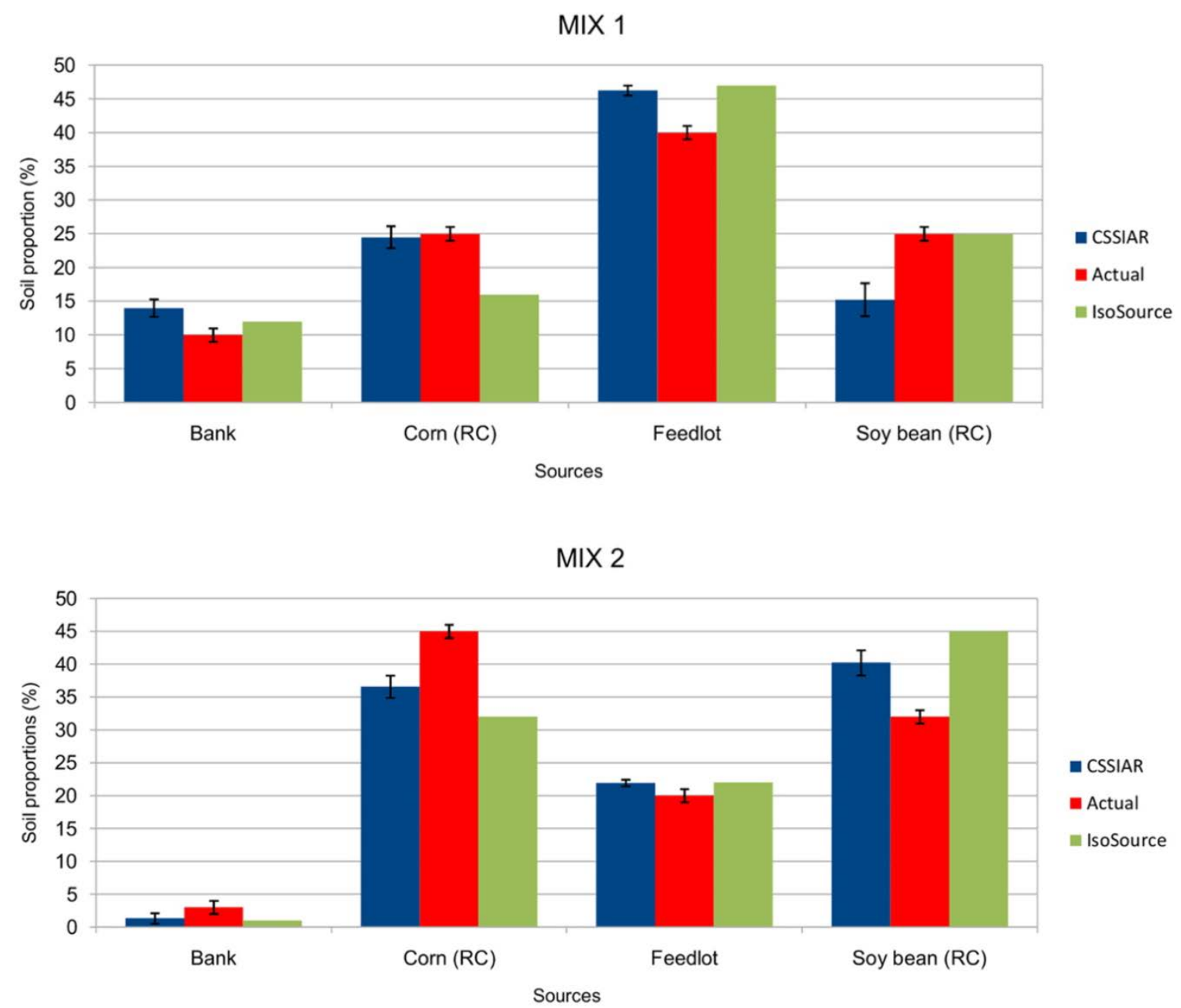

2 Figure 3. Comparision between actual and calculated soil proportion in the artificial mixed samples.The 3 error bars represent the associated uncertainty when preparing the artificial mixtures. For the calculated 4 soil proportions the standard deviation provided by the mixing model was included as error bar (Adapted 5 from Torres Astorga et al. 2018). 

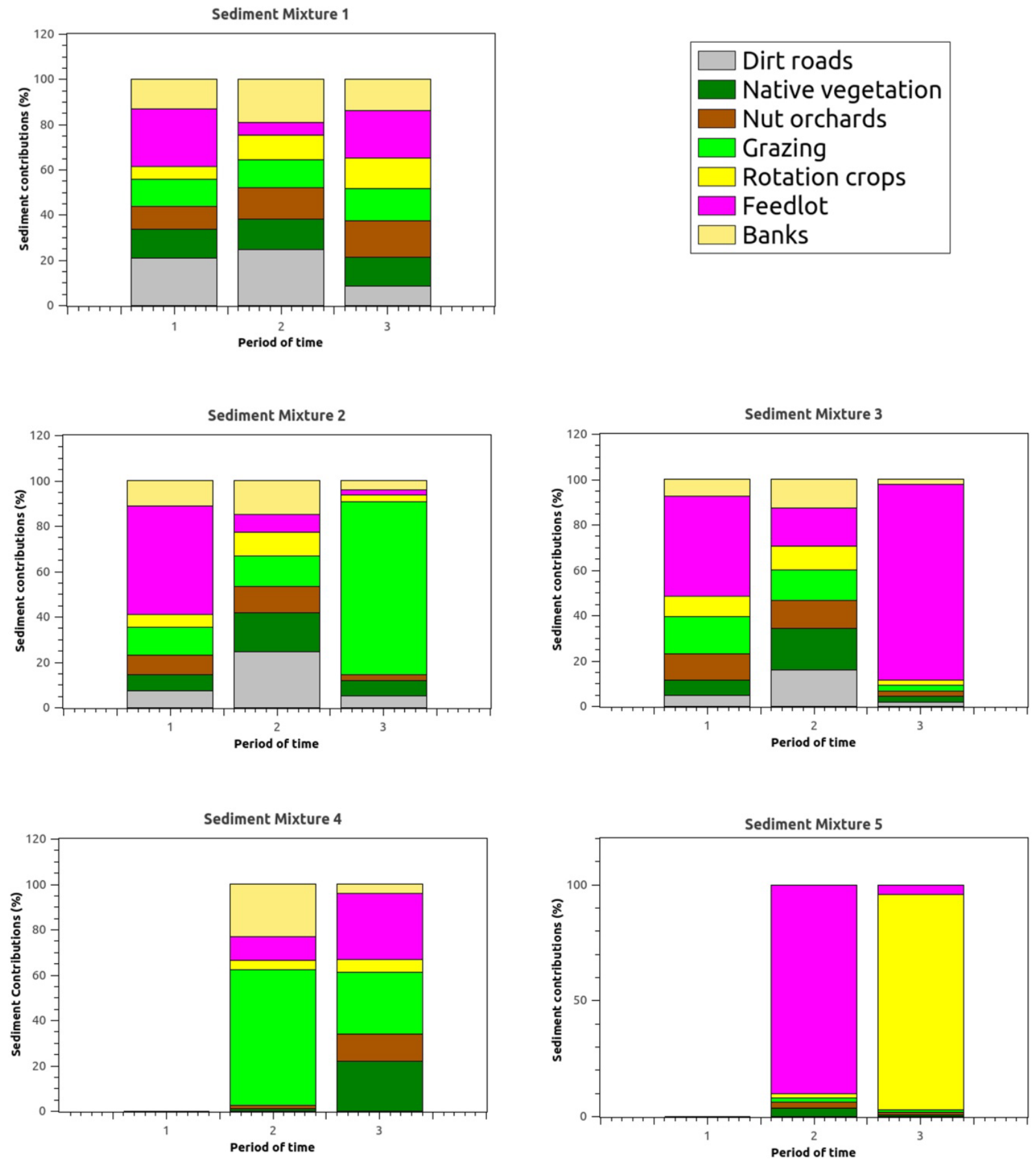

Figure 4. Sediment mixtures collected in three channels of the catchment at (1) the end of rainy season, after harvesting; (2) the end of dry season; (3) middle of rainy season. 